Results: SIV uptake was high in those $\geq 65$ years old $(82.3 \%$ and $80.7 \%$ in 2006-07 and 2015-16 respectively). However, it was significantly lower in other age groups, but improved over time with $51.9 \%$ and $61.9 \%$ in the $45-64$ year age group, and $32.3 \%$ and $50.1 \%$ in the $<45$ year age group being vaccinated in 2006-07 and 2015-16 respectively. While $64.9 \%$ of the vaccinations in those $\geq 65$ years old occurred by the 3rd November (week 9 in Graph 1), in time to mount a protective immune response before the influenza activity becomes substantial in the UK, only $38.9 \%$ in the $45-64$ year and $26.2 \%$ in the $<45$-year age group without any other reason for vaccination received SIV before this date (Graph 1). Men, those without additional indications for vaccination, and those on single DMARDs were significantly less likely to be vaccinated.

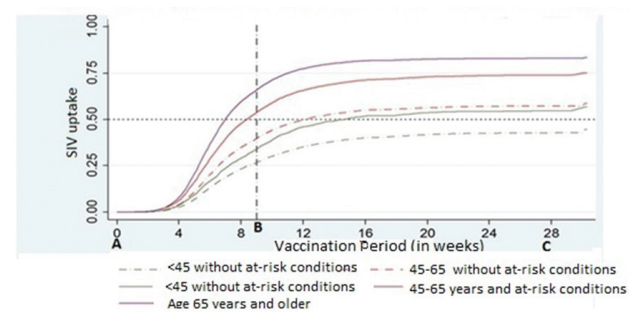

Yearly vaccination uptake was determined from 1 September (A) to $31^{\text {st }}$ M arch of the next year (C). $B$ indicates the point when influenza activity nomally starts to become substantial in the UK

Conclusions: The uptake of SIV is low in the under $65 \mathrm{~s}$, and many do not get vaccinated in time to confer immunity. Additional effort is required to promote the timely uptake of SIV in this population. To our knowledge, this is the first study to assess temporal trends in uptake of SIV among AIRDs and to compare uptake across different AIRDs.

Disclosure of Interest: None declared

DOI: 10.1136/annrheumdis-2018-eular.4519

\section{FRI0620 LOW EDUCATIONAL ATTAINMENT IS ASSOCIATED WITH POOR PATIENT STATUS AT THE INITIAL VISIT OF PATIENTS WITH RHEUMATOID ARTHRITIS (RA) OR OSTEOARTHRITIS (OA) AT THE INITIAL VISIT TO A RHEUMATOLOGY SETTING, WITH SIMILAR PATTERNS IN PATIENTS WITH EITHER DIAGNOSIS}

J. Schmukler ${ }^{1}$, I. Castrejon ${ }^{1}$, T. Pincus ${ }^{1}$, J. Block ${ }^{1} .{ }^{1}$ Rheumatology, Rush University Medical Center, Chicago, United States

Background: Low educational attainment is associated with a higher prevalence, morbidity, and mortality of many diseases, including rheumatoid arthritis (RA) (J Chronic Dis 1985; 38:973-84) and osteoarthritis (OA) (J Clin Epidemiol 1992;45:139-47). These associations often are attributed to limited access of disadvantaged people to medical services (Ann Intern Med 1998;129:412-6), although some have suggested that these differences are explained primarily by differences in patient self-management (Ann Intern Med 1998;129:406-11).

Objectives: To study clinical status of patients with RA or OA, all of whom had access to rheumatology care, at their initial visit.

Methods: All patients with all diagnoses seen at an academic rheumatology site complete a self-report multidimensional health assessment questionnaire (MDHAQ) at each visit. MDHAQ includes 3 0-10 scales for physical function (FN), pain (PN) and global assessment (PATGL), compiled into a 0-30 routine assessment of patient index data (RAPID3). Patient-reported FN, PN, PATGL and RAPID3 were compared in new patients with a primary diagnosis of either RA $(n=66)$ or $O A(n=66)$ at a first visit in 3 groups according to years of formal education, $<12,12$, and $>12$ years, using analysis of variance (ANOVA).

Results: Mean MDHAQ scores were quite similar in OA vs RA, and varied similarly according to education level (table 1). In all patients, mean RAPID3 was 15.4 in OA vs 15.3 in RA; in those with $<12$ years, 18.2 in OA vs 19.8 in $R A$; in those with 12 years, 15.9 in $O A$ vs 16.0 in $R A$; in those with $>12$ years, 14.0 in $O A$ vs 13.7 in $R A$ ( $p=0.11$ for $O A, p=0.04$ for $R A$ ) (table 1 ). FN scores were 3.9 in both groups with $<12,3.3$ in both groups with 12 , and 2.3 in OA vs 2.4 in RA patients with $>12$ years of education ( $p=0.02$ for $O A, p=0.08$ for $R A$ ). PN scores were 7.3 and 8.5 for OA vs RA with $<12$ years, 7.1 and 6.2 for OA vs RA with 12 years, and 6.7 vs 5.9 for $O A$ vs $R A$ patients with $>12$ years of education $(p=0.69$ for $O A$, $\mathrm{p}=0.02$ for RA). PATGL was 7.0 vs 7.4 for $O A$ vs $R A$ with $<12$ years, 5.5 and 6.5 for $O A$ vs RA with 12 years, and 5.1 and 5.4 in OA vs RA patients with $>12$ years of education ( $p=0.14$ for $O A, p=0.12$ for $R A$ ).
Table 1 Mean \& standard deviation (SD) for 0-10 physical function, pain, patient global assessment and 0-30 RAPID3 of patients with RA or OA at first visit, by formal education level

\begin{tabular}{|c|c|c|c|c|c|}
\hline \multirow{2}{*}{$\begin{array}{l}\mathrm{OA}- \\
\text { measures }\end{array}$} & \multirow{2}{*}{$\begin{array}{l}\text { Total } \\
\mathrm{N}=66\end{array}$} & \multicolumn{4}{|c|}{ Groups by level of education (years) } \\
\hline & & $\begin{array}{l}<12 \\
(n=12)\end{array}$ & $\begin{array}{l}12 \\
(n=21)\end{array}$ & $\begin{array}{l}>12 \\
(n=33)\end{array}$ & $\mathbf{p}$ \\
\hline $\begin{array}{l}\text { Function (0- } \\
10)\end{array}$ & $2.9(2.0)$ & $3.9(1.5)$ & $3.3(2.3)$ & $2.3(1.7)$ & 0.02 \\
\hline Pain $(0-10)$ & $6.9(2.3)$ & $7.3(1.7)$ & $7.1(2.4)$ & $6.7(2.5)$ & 0.69 \\
\hline PATGL (0-10) & $5.6(2.9)$ & $7.0(2.1)$ & $5.5(3.1)$ & $5.1(2.9)$ & 0.14 \\
\hline RAPID3 (0-30) & $\begin{array}{l}15.4 \\
(6.0)\end{array}$ & $18.2(3.9)$ & $15.9(6.8)$ & $14.0(5.9)$ & 0.11 \\
\hline RA - & Total & \multicolumn{4}{|c|}{ Groups by level of education (years) } \\
\hline measures & $\mathrm{N}=66$ & $\begin{array}{l}<12 \\
(n=12)\end{array}$ & $\begin{array}{l}12 \\
(n=21)\end{array}$ & $\begin{array}{l}>12 \\
(n=33)\end{array}$ & $\mathbf{p}^{*}$ \\
\hline $\begin{array}{l}\text { Function (0- } \\
\text { 10) }\end{array}$ & $2.9(2.2)$ & $3.9(3.0)$ & $3.3(2.1)$ & $2.4(1.8)$ & 0.08 \\
\hline Pain $(0-10)$ & $6.4(2.9)$ & $8.5(1.5)$ & $6.2(3.4)$ & $5.9(2.7)$ & 0.02 \\
\hline PATGL (0-10) & $6.0(3.0)$ & $7.4(3.1)$ & $6.5(3.3)$ & $5.4(2.8)$ & 0.12 \\
\hline RAPID3 0-30) & $\begin{array}{l}15.3 \\
(7.2)\end{array}$ & $19.8(6.3)$ & $16.0(8.1)$ & $13.7(6.5)$ & 0.04 \\
\hline
\end{tabular}

Conclusions: Low education was associated with RAPID3 and all component scores similarly in RA and OA. Differences according to formal education level were greater than by diagnosis, which were negligible. These variations do not appear attributable to differences in access to medical services.

Disclosure of Interest: J. Schmukler: None declared, I. Castrejon: None declared, T. Pincus Shareholder of: Dr. Pincus holds a copyright and trademark on MDHAQ and RAPID3 for which he receives royalties and license fees. All revenue is used to support further development of quantitative questionnaire meas ures for patients and doctors in clinical rheumatology care., J. Block: None declared

DOI: 10.1136/annrheumdis-2018-eular.5874

\section{FRI0621 HOSPITAL ADMISSIONS AND READMISSIONS IN PATIENTS WITH RHEUMATOID ARTHRITIS. ASSOCIATED FACTORS AND DIRECT HEALTH-CARE COSTS IN A THIRD LEVEL UNIVERSITY HOSPITAL}

J. E. Ruiz-Sará ${ }^{1}$, N. Lozano-Rivas ${ }^{1}$, P. Castillo Dayer ${ }^{1}$, C. García-Belando ${ }^{1}$, A. Paños-Iniesta ${ }^{1}$, L. F. Linares ${ }^{1}$, A. Bermudez ${ }^{1}$, F. A. Martínez-Angosto ${ }^{1}$, J. Martínez-Ferrín ${ }^{1}$, M. J. Moreno ${ }^{1}$, M. Castaño ${ }^{1}$, P. Mesa del Castillo ${ }^{1}$, F. García Gambín $^{2}$, F. Andrade Rodado ${ }^{3}$, C. Marras-Fernández Cid ${ }^{1} .{ }^{1}$ Rheumatology Department. University Hospital Virgen Arrixaca, ${ }^{2}$ Evaluation departmen University Hospital Virgen Arrixaca, Murcia, ${ }^{3}$ Intensive Care Unit. Vega Baja Hospital, Orihuela. Alicante, Spain

Background: In last years, the direct health-care costs derived from admissions and readmissions to Rheumatology departments of patients with Rheumatoid Arthritis (RA) have diminished. Presumably, the higher survival rate and the amount of comorbidities of these patients have derived in an increased of admissions and direct costs to other medical and surgical departments.

Objectives: To describe the admission and readmission causes of all patients with RA admitted during 2015 and 2016 and to identify factors associated to read mission. Finally to estimate the costs derived from these events in the same period.

Methods: All electronic medical reports were revised; demographic, medical and therapeutic data, as well as diagnosis at discharge were collected. A descriptive analysis followed by a logistic regression analysis were done to identify readmission-associated variables. Financial analysis was done by calculating the price of the stay according to established in 2015-scale.

Results: 240 admissions of 158 patients were found. Mean age 63,8 years, $69 \%$ women and mean evolution of RA of 13,1 years. At admission, $53 \%$ were on ora steroids and $45 \%$ with synthetic DMARD. Admissions were mainly distributed in Internal Medicine department (26\%). Infections were the most frequent admission cause (33\%), followed by cardiovascular events $(20 \%)$ and oncological processes (13\%). Forty-nine patients (31\%) were readmitted, $47 \%$ due to infections. Age (OR/year $1.02 \mathrm{Cl} 95 \% 1.00-1.04$ ), diabetes (OR $2.1 \mathrm{Cl} 95 \% 1.1-4.4$ ) and chronic kidney disease (OR $3.3 \mathrm{CI} 95 \% 1.0-10.2)$ were the associated risk factors. There were a total of 2172 days of stay with an estimated cost of 530420 euros and 783 days of stay due to readmissions with a total cost of 203218 euros. Departments which generated more costs either for admissions or readmissions were Oncology (65064 euros/19585 euros respectively) and Intensive Care (68011 euros/42651 